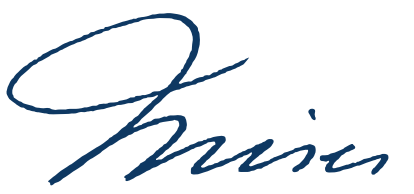

\title{
O Papel do Estado na Origem e na Evolução Institucional da Moeda à Luz da Escola Austríaca de Economia
}

\author{
Otavio Ferrari Piaskowski I (1) 0000-0002-4728-5328 \\ Universidade Tuiuti do Paraná, Curitiba, Paraná, Brasil
}

\begin{abstract}
Resumo: O presente artigo tem como objetivo discutir o papel do Estado na origem e evolução institucional da moeda à luz da Escola Austríaca de Economia. Essa pesquisa surgiu no contexto do desenvolvimento das moedas virtuais, que têm atraído considerável interesse acadêmico nos últimos tempos. Para tal, utilizamos a teoria da origem da moeda de Menger (1985; 2007; 2009), o conceito de ordem ampliada de Hayek (1948a; 1948b; 2017), a teoria de processos de mercado de Barbieri (2001) e a teoria das instituições de Angeli (2007). Considerando o contexto atual das moedas virtuais, bem como o funcionamento da moeda de curso forçado, entende-se que o Estado age como uma trava no processo, efetuado pelo mercado, de seleção das moedas que melhor cumprem as funções básicas de meio de troca, reserva de valor e unidade de conta. Da mesma forma, o Estado prejudica o processo de correção das falhas no funcionamento do sistema financeiro.
\end{abstract}

Palavras-chave: Escola Austríaca, Moeda, Origem, Evolução, Estado.

${ }^{\text {I }}$ Professor pós-graduado de História, com ênfase em História Cultural e enfoque em Antropologia (Faculdades Integradas
Espírita - FIES - 2019). Licenciatura em História (Universidade Tuiuti do Paraná - UTP - 2017). E-mail: ofpias@yahoo.com.br. 


\title{
The role of the State in the Origin and Institutional Evolution of Money in the Light of the Austrian School of Economics
}

\begin{abstract}
This paper aims to discuss the State's role in the origin and in the institutional evolution of money in the light of the Austrian School of Economics. This research developed from the context of virtual currencies, which has attracted considerable academic interest in the last few years. Therefore, we employed the theory of the origin of money according to Menger $(1985,2007,2009)$, the concept of extended order proposed by Hayek $(1948,1948 a, 2017)$, the theory of market processes as stated by Barbieri (2001), and the theory of institutions developed by Angeli (2007). Considering the context of the virtual currencies and the behavior of the fiat money, it is understood that the State acts as a clog in the process, performed by the market, of the selection of currencies that best carries out their essential functions of medium of exchange, unit of account and storage of value. Similarly, the State harms the process of correction of flaws in the functioning of the financial system.
\end{abstract}

Keywords: Austrian School, Money, Origin, Evolution, State.

\section{El Papel del Estado en la Origen y en la evolución institucional de la moneda a la luz de la Escuela Austríaca de Economía}

\begin{abstract}
Resumen: Este artículo tiene como objetivo discutir el papel del estado en el origen y evolución institucional de la moneda a la luz de la Escuela Austríaca de Economía. Esta investigación emergió del contexto de desarrollo de las monedas virtuales, que han atraído considerable interés académico en los últimos años. Para ello, utilizamos la teoría del origen de la moneda de Menger (1985, 2007, 2009), el concepto de orden extendido de Hayek (1948a, 1948b, 2017), la teoría de los procesos de mercado de Barbieri (2001), y la teoría de las instituciones de Angeli (2007). Considerando el contexto actual de las monedas virtuales y del funcionamiento de la moneda de curso forzado, se entiende que el Estado actúa como una barrera en el proceso, llevado a cabo por el mercado, de selección de las monedas que mejor cumplen con sus funciones básicas de medio de cambio, reserva de valor y unidad de cuenta. Asimismo, el Estado obstaculiza el proceso de corrección de las fallas de operación del sistema financiero.
\end{abstract}

Palabras clave: Escuela Austríaca, Moneda, Origen, Evolución, Estado. 


\section{Introdução}

Ao longo dos últimos anos, baseada no amplo desenvolvimento da tecnologia no campo das comunicações, a história do dinheiro vem experimentando uma nova descoberta: a moeda virtual $^{1}$. Tal descoberta tem como seu principal exemplo o Bitcoin. Para Ulrich (2014, p. 15), “(...) o Bitcoin é uma forma de dinheiro, assim como o real, o dólar ou o euro, com a diferença de ser puramente digital e não ser emitido por nenhum governo.". Em outras palavras, é uma moeda $100 \%$ privada, criada e administrada pelos indivíduos no mercado. Com base nesse tema atual, algumas pesquisas começaram a tratar não apenas dessas moedas virtuais, mas também de rever e construir novas perspectivas sobre a origem e a evolução da moeda na história humana (ZELMANOVITZ, 2013; GRAF, 2015; GRAF, 2016; BERNARDO; BERNARDELLI; NORI, 2019; CATÃO; PINTO, 2020). A junção do contexto dessas novas moedas com as pesquisas citadas acima chamou a atenção do pesquisador para o estudo desse tema.

Quando se estuda a eclosão da moeda e seu desenvolvimento posterior, invariavelmente se discute sobre o papel do Estado $^{2}$ neste processo, dado que a imensa maioria das moedas utilizadas em circulação hoje em dia partem do governo, através do banco central. Inclusive, argumenta Hayek, o controle do governo sobre esse processo é tomado como sendo um “(...) elemento essencial da soberania [do poder governamental]"3 (HAYEK, 1990, p. 28). Em outras palavras, o aparato governamental tomou para si esse processo de criação e evolução da moeda. Esse é o problema com o qual nos depararemos ao longo desse artigo.

A partir do contexto histórico, das discussões acadêmicas e do problema proposto no parágrafo anterior, o presente artigo procurará responder a seguinte problemática: Qual o papel do Estado na origem e na evolução institucional da moeda? Para responder a essa problemática, este artigo utilizará como base as discussões teóricas promovidas pela Escola Austríaca de Economia.

Em particular, são quatro as teorias desenvolvidas por esta escola que fornecem suporte para esta pesquisa: A Teoria da Origem da Moeda, desenvolvida por Carl Menger (1985; 2007; 2009); o conceito de "ordem ampliada", desenvolvida por Friedrich August von Hayek (1948a; 1948b; 2017); a noção de processos de mercado para Fábio Barbieri (2001); e a teoria das instituições, desenvolvida por Eduardo Angeli (2007). Menger (2007) fundamenta a sua teoria a partir da tese de que a moeda surge não de uma ação governamental ou de um ato legislativo, mas das interações entre indivíduos no mercado. Já Hayek (2017), entende que a "ordem ampliada" envolve as instituições que surgem espontaneamente, sem a participação de um planejamento central ou racional nesse processo. Barbieri (2001) observa que o processo de mercado é um fenômeno evolucionário, em que planos são testados continuamente, de modo que alguns deles sobrevivem a esse teste, enquanto outros precisam de alterações ou

\footnotetext{
${ }^{1}$ Ao adotar a nomenclatura "moeda virtual", está se seguindo a nomenclatura adotada por Catão e Pinto (2020).

${ }^{2}$ Seguindo o editorial da "Mises: Revista Interdisciplinar de Filosofia, Direito e Economia", bem como do Instituto Ludwig von Mises Brasil (IMB) e considerando a opção feita por Lorenzon (2017), adotou-se nesta pesquisa a grafia da palavra "estado" com letras minúsculas.

${ }^{3}$ Tradução livre do inglês: "[...] essential atribute of sovereignty."
} 
mesmo serem abandonados. Por fim, Angeli (2007) depreende que as instituições reduzem o grau de incerteza que existe no mercado, e que promovem uma certa previsibilidade ao comportamento dos indivíduos.

Com base no problema exposto e na apresentação do arcabouço teórico, este artigo tem como objetivo geral: Discutir o papel do estado na evolução institucional da moeda desde a sua origem. De modo a realizar esse intento, foram definidos os seguintes objetivos específicos: 1. Apresentar a teoria da origem da moeda conforme Menger (1985; 2007; 2009); 2. Apresentar o conceito de "ordem espontânea" em Hayek (1948a; 1948b; 2017); 3. Apresentar a noção de processo de mercado em Barbieri (2001); 4. Apresentar a teoria das instituições conforme Angeli (2007); 5. Discorrer sobre o papel do Estado na origem e na evolução institucional da moeda.

Em termos metodológicos, esta pesquisa compõe-se de um artigo teórico, com base em elementos da Escola Austríaca de Economia, fundamentado em pesquisa bibliográfica, de modo a estabelecer a discussão do tema proposto. Sua importância está em uma contribuição teórica para a questão da moeda, conforme foi amplamente discutida, nos últimos tempos, no seio desta escola de pensamento. Este artigo, é necessário apontar, não esgota o assunto, mas busca recomendar futuras pesquisas que possam teorizar sobre as soluções para o problema do monopólio que o Estado tem sobre a moeda nos tempos atuais.

\section{Fundamentação teórica}

A fundamentação teórica deste artigo se divide em duas partes. Na primeira, serão apresentadas a teoria da origem da moeda segundo Carl Menger (1985; 2007; 2009) e o conceito de "ordem ampliada", conforme Friedrich Hayek (1948a; 1948b; 2017). Na segunda parte, serão apresentadas a teoria do processo de mercado, conforme Fábio Barbieri (2001), e a teoria das instituições, segundo Eduardo Angeli (2007).

\subsection{A Teoria da Origem da Moeda em Menger e a Ordem Ampliada em Hayek}

A teoria da origem da moeda é uma teoria que permeia grande parte da obra de Carl Menger ${ }^{4}$ De maneira geral, para Menger (2007), a origem da moeda se dá a partir de quatro estágios: 1. Uma economia de troca direta; 2. O surgimento de mercadorias que possuem uma maior "negociabilidade" ; 3. A aceitação dessas mercadorias como moeda; 4. A chancela dessa moeda por parte do Estado.

O primeiro estágio dessa formação parte da construção de uma economia de escambo. Para Menger (2007), nesta etapa, o ser humano troca mercadorias de forma direta, isto é, a troca de um bem para outro no sentido de consumir o bem adquirido imediatamente, para suprir as suas necessidades. Neste estágio, a possibilidade de haver trocas entre indivíduos é

\footnotetext{
${ }^{4}$ Hans Sennholz (1992) observa que grande parte da obra de Carl Menger refere-se à teoria monetária e suas discussões sobre o padrão ouro. E destas, a teoria sobre a origem da moeda ocupa um lugar central, pois é objeto de reflexão por parte do autor austríaco em seus dois livros: "Principles of Economics" (Princípios de Economia Política), publicado em 1871 e "Investigations into the method of the Social Sciences with special reference to economics", publicado em 1883.

${ }^{5}$ Tradução livre do inglês: "Marketability"
} 
extremamente remota, devido a grande quantidade de coincidências de desejos, desses desejos serem conhecidos por ambos os agentes, e de estarem no mesmo lugar e ao mesmo tempo, algo que seria muito difícil no mundo real (MENGER, 2009) .

Com o passar do tempo, Menger (2007) argumenta que passam a surgir bens que possuem uma maior "negociabilidade" quando comparada com a de outros produtos. Trocando em miúdos, alguns bens possuem uma facilidade maior de serem trocados no mercado por outros. Dessa forma, o comércio deixa de ser direto para se transformar em uma atividade indireta, em que o indivíduo troca o seu produto por outro mais negociável, antes de comprar o bem que iria satisfazer as suas necessidades.

Aos poucos, entra-se no terceiro estágio do surgimento da moeda, em que esse bem considerado mais negociável passa a ser considerado o meio de troca universal em um número cada vez maior de mercados. Em suma, esse bem passa a exercer a função de moeda nos mercados. De maneira geral, tais meios de troca universais passaram a ser os metais preciosos (MENGER, 2009). Tal processo, argumenta Menger (2007), acontece de uma forma inteiramente voluntária, sem participação de um planejamento central ou mesmo de uma legislação nesse sentido.

Ao cabo desse processo, quando já tinha se estabelecido uma moeda, e que ela era aceita dentro de um determinado território, é que o estado teria a sua influência sobre esse processo. A sua função, para Menger (2007), é a de regular e a de aperfeiçoar a moeda, como no caso dos metais preciosos, cunhando moedas e certificando o dinheiro como sendo confiável.

Portanto, o surgimento da moeda, conforme Carl Menger (2007), pode ser resumido como sendo um longo processo de mercado, sem a participação do estado até o seu último estágio. Desta forma, o economista austríaco julga a tentativa de considerar o dinheiro como uma criação estatal como sendo "a-histórica"7;8 (MENGER, 2009, p. 17).

Essa construção que, segundo Barbieri e Feijó (2013), aproxima a teoria da história na ciência econômica teve grande impacto para a obra de Menger. Em seu segundo livro, Investigations into the Method of the Social Sciences with special reference to Economics ${ }^{9}$ (MENGER, 1985), ele extrapola a origem do dinheiro para outras importantes instituições humanas que teriam processos similares. Assim, tanto o dinheiro como a linguagem, o direito, os mercados e o próprio estado, deveriam ser explicados não a partir de uma origem "pragmática"10, ou

\footnotetext{
${ }^{6}$ A existência apenas de um sistema de troca direta, comenta Mises (2010), tornaria o estudo da ciência econômica inviável. Em suas palavras: "Num mundo em que só se praticasse a troca direta, uma teoria da troca indireta seria mero passatempo intelectual. É pouco provável que os economistas de tal mundo se ocupassem com os problemas da troca indireta, moeda e tudo o mais. É menos provável ainda que a ciência econômica viesse a existir nesse mundo imaginário. Entretanto, em nosso mundo real, esses estudos são uma parte essencial da teoria econômica." (MISES, 2010, p. 95).

${ }^{7}$ Tradução livre do inglês: "unhistorical".

${ }^{8}$ Concordando com a tese de Menger, Ludwig von Mises observa que “O conceito de dinheiro como sendo uma criação da Lei e do Estado é claramente insustentável. Não consegue ser justificado por nenhum fenômeno do mercado" (MISES, 1953, p. 69). (Tradução livre do inglês: "The concept of Money as a creature of Law and State is clearly untenable. It is not justified by a single phenomenon of the market.").

${ }^{9}$ Em tradução livre para o português: "Investigações sobre o Método das Ciências Sociais com referência espcial à Economia.". Esta obra ainda não possui tradução para a língua portuguesa.
}

${ }^{10}$ Tradução livre do inglês: “Pragmatic" (MENGER, 1985, p. 147). 
seja, fruto de uma legislação ou de um planejamento central, mas de uma origem "orgânica"11, isto é, um processo "natural"12, guiado tão somente pelos interesses humanos individuais em cada grupo humano, ao longo do tempo.

Essas considerações sobre a segunda obra de Menger ajudam a explicá-la como sendo uma das origens da teoria do conhecimento de Friedrich Hayek, que analisaremos a seguir. Para Hayek (1948a), há limitações no paradigma do equilíbrio para a ciência econômica. Tal paradigma oferece boas explicações para as ações e planos de uma única pessoa. O problema está na aplicação deste paradigma para os indivíduos em sociedade. Ali, com o passar do tempo, os planos alteram-se. Expectativas não se concretizam. Pessoas declaram falência. Outras obtêm lucro e se tornam grandes empresários. Novos produtos são lançados, uns tendo sucesso e outros não. Logo, torna-se extremamente complicado observar situações de equilíbrio neste mundo de diferentes planos e ações (HAYEK, 1948a).

Desta forma, Hayek (1948a) argumenta que a ciência econômica deve, ao contrário, atentar para o intricado processo de compatibilização dos planos entre empreendedores e consumidores. Ou seja, a coincidência entre os desejos dos consumidores e os produtos ofertados pelos vendedores. Assim, a ciência econômica perde um pouco do seu caráter formal para ganhar uma atividade mais contemplativa.

Assim, como solucionar esse problema da compatibilização de planos entre os agentes econômicos? Há três tipos de solução: um sistema centralizado de decisões econômicas; um sistema descentralizado ou um sistema misto. Hayek (1948b) nega a primeira solução, argumentando que um órgão de planejamento central da economia não tem a capacidade de descobrir dados que são continuamente descobertos no intricado processo de compatibilização dos planos entre os agentes econômicos descritos acima ${ }^{13}$.

Passando à segunda solução, este decididamente é o favorecido por Hayek. Guiado pelo sistema de preços, o economista austríaco defende (1948b) que um sistema descentralizado de decisões econômicas permite um ajustamento maior e mais veloz às mudanças da quantidade de recursos disponíveis e dos gostos dos consumidores. Em suas palavras: "Precisamos de descentralização porque apenas deste modo nós podemos assegurar que o conhecimento de circunstâncias particulares de tempo e espaço possam ser prontamente utilizados"14 (HAYEK, 1948b, p. 84). Assim, um sistema descentralizado é superior a um centralizado, pois naquele ocorre uma maior descoberta e compatibilização dos planos entre os agentes econômicos.

Por fim, um sistema misto seria uma alternativa ao sistema descentralizado, permitindo um maior controle do processo econômico? Hayek (1948b) sustenta que tal sistema é insustentável,

\footnotetext{
${ }^{11}$ Tradução livre do inglês: “Organic" (MENGER, 1985, p. 145).

${ }^{12}$ Tradução livre do inglês: "Natural” (MENGER, 1985, p. 130).

${ }^{13}$ Essa construção e argumentação feita pelo economista austríaco é parte integrante daquilo que Barbieri (2004) chamou de "Crítica Indireta" hayekiana ao Socialismo, no contexto do debate do cálculo econômico socialista. Para um tratamento aprofundado dessas críticas ao Socialismo desenvolvidas por Hayek, ver Barbieri (2004, p. 143-167).

${ }^{14}$ Tradução livre do inglês: "We need decentralization because only thus can we insure that the knowledge of the particular circumstances of time and place will be promptly used."
} 
uma vez que interfere no funcionamento dos preços e, consequentemente, no processo de disseminação de informações individuais para outros indivíduos. Conforme ele argumenta:

Nós precisamos olhar para o sistema de preços como sendo um mecanismo de comunicação de informações se queremos compreender sua real função - uma função que, claramente, realiza essa função de modo cada vez mais imperfeito conforme os preços ficam cada vez mais rígidos. (HAYEK, 1948b, p. 86) ${ }^{15}$

Desta forma, pode-se concluir que apenas um sistema descentralizado de tomada de decisões econômicas permite uma ordem econômica racional e, acima de tudo, funcional. Além disso, ele permite que novas descobertas e planos sejam compatibilizados, o que confere maior eficiência à economia do dia a dia (HAYEK, 1948b)

A partir deste sistema descentralizado, surge aquilo que Friedrich Hayek chamou de "ordem ampliada" (2017, p. 13). Esta ordem engloba as instituições que para o economista austríaco surgiram aos poucos, através de um processo espontâneo, isto é, sem qualquer planejamento racional por parte de um indivíduo ou de um órgão. Essas instituições, para Hayek (2017), são o mercado, a lei, a linguagem, a propriedade privada, a justiça, a civilização ocidental, entre outras.

Com esta ordem extremamente intricada, ela apresenta, para o ser humano, dificuldades extremas de ser administradas de uma forma central. Tentar administrar essas forças ou, nas palavras de Hayek, “agarrar as rédeas” (2017, p. 34) desse processo, é um erro grave, porque ignora a complexidade dos eventos que se pretende controlar. Ignora também, todo o desenvolvimento pretérito dessas instituições que, sobrevivendo ao teste do tempo, foram contornando falhas e se tornando ainda mais eficientes em sua atividade.

Desta forma, torna-se claro o alerta do autor sobre uma maior participação do estado nessas instituições espontâneas. Em suas palavras: "[...] a civilização pode se difundir, mas não é provável que avance muito sob direção de um governo que toma dos cidadãos a direção das questões cotidianas" (HAYEK, 2017, p. 46).

\subsection{A Teoria de Processos de Mercado conforme Barbieri e a Teoria das Instituições segundo Angeli}

Nesta segunda seção da fundamentação teórica, apresenta-se brevemente as considerações sobre o processo evolucionário de mercado, tal como preconizado por Fábio Barbieri (2001), e a teoria das instituições, segundo Eduardo Angeli (2007). Ambas as contribuições sistematizam e aprofundam as discussões de Friedrich Hayek sobre os dois temas, o que auxilia na compreensão e utilização do programa de pesquisa hayekiano para este artigo sobre o papel do estado na origem e no desenvolvimento da moeda.

A contribuição de Barbieri (2001) caminha no sentido de realizar uma analogia do processo de mercado com alguns elementos da filosofia da ciência. Em essência, aproxima, no estudo

\footnotetext{
${ }^{15}$ Tradução livre do inglês: "We must look at the price system as such a mechanism for communicating information if we want to understand its real function - a function which, of course, it fulfils less perfectly as prices grow more rigid.".
} 
das trocas econômicas entre os agentes, a teoria do conhecimento de Friedrich Hayek com o racionalismo crítico de Karl Popper.

Desta forma, Barbieri (2001) compreende o mercado a partir de uma perspectiva evolucionária. Neste processo, cada um dos agentes econômicos individualmente formula hipóteses, planos e ações sobre a realidade econômica. Como esta realidade não se apresenta de uma forma acabada e presente nas mentes de cada um, estas hipóteses, planos e ações necessariamente são falíveis, ou seja, passíveis de erros. Estas teorias sobre a realidade econômica então, passam por um processo de crítica e refutação em meio ao mercado, semelhante ao que ocorre nas pesquisas científicas, conforme a teoria de Popper. Essa crítica e refutação é conduzida pelo mercado através do mecanismo de lucros e perdas, que comunica aos outros indivíduos tais resultados, conforme defendia Hayek. Assim, planos que mais se aproximam dessa realidade externa às mentes desses indivíduos são premiados através do lucro, enquanto os que estão mais longe ou enfrentam prejuízos, ou precisam reformular seus planos para se adequar a essa realidade.

Esse processo complexo descrito acima possui uma grande vantagem na condução das decisões empresariais e na organização dos mercados: permite um maior aprendizado aos agentes econômicos. Esse aprendizado surge da eliminação das "[...] ações incompatíveis com as realidades subjacentes de preferências e disponibilidade de recursos" (BARBIERI, 2001, p. 180). Logo, empresários e futuros empreendedores modificam seus planos e buscam, no sucesso ou na falha de outros empreendedores, um guia para lidar com a falibilidade do mercado e auferir lucros para si.

Passando à contribuição de Angeli (2007), ele sistematiza a noção de instituições em Friedrich Hayek. Tal sistematização é importante, pois, como afirma Barbieri (2019), a obra do economista austríaco se apresenta em fragmentos, uma vez que ele não escreveu uma obra que integrasse suas contribuições para diversas áreas do conhecimento, como Direito, Economia, Política, História, entre outras.

A teoria das instituições em Hayek, para Angeli (2007), parte da noção de incerteza, que abarca o indivíduo tanto no sentido de tratar da realidade complexa que o atinge (incerteza de tipo "procedimental"), quanto no de que há uma inexistência de informações completas sobre o futuro, pois ele é constantemente alterado pela ação dos indivíduos (incerteza de tipo "fundamental").

Assim, para Angeli (2007), a teoria das instituições são respostas a esse ambiente de incerteza por parte dos indivíduos. Tal resposta, é necessário dizer, da ação humana que, buscando seus próprios interesses, acaba por se afastar de qualquer planejamento ou intenção mais profunda que levou à criação dessas instituições. Logo, colocando de outra forma, as instituições em Hayek são criações espontâneas da sociedade, que, ao longo do tempo, introduz, também de forma espontânea, modificações nessas instituições para que elas se adaptem aos novos ambientes sociais.

A função das instituições em Hayek, argumenta Angeli (2007), é de trazer alguma previsibilidade para as ações dos indivíduos, delimitando, de forma parcial, as possíveis respostas dos indivíduos diante das incertezas do mundo ao redor deles. Tal função é construída 
em conjunto com as normas, as regras morais e as leis de determinado grupo humano. Dessa forma, apesar de restringir as respostas dos indivíduos, não elimina por completo possíveis transgressões dessas normas por parte da ação humana individual.

\section{Discussão sobre o papel do Estado na criação e na evolução da moeda}

Nesta seção, volta-se ao objeto de estudo, que é o papel do estado no processo de criação e evolução da moeda, tendo como base na apresentação das teorias de Menger (1985; 2007; 2009), Hayek (1948a; 1948b; 2017), Barbieri (2001) e Angeli (2007), feitas no capítulo anterior. Com base nessas teorias, podemos desenvolver sete discussões que serão aprofundadas a seguir. Respectivamente, elas versam, primeiro, sobre a origem da moeda; segundo, o papel do costume nesse processo; terceiro, a função da moeda no processo de mercado; quarto, sobre a possibilidade de planejamento central da moeda, na figura de um Banco Central; quinto, algumas observações sobre a moeda sem o estado; sexto, sobre um futuro sistema monetário privado; e, finalmente, sobre a necessidade de chancela da moeda por parte do Estado.

Sobre a origem da moeda, pode-se afirmar que o processo de criação da moeda não ocorre apenas através de processos legislativos, mas também ela pode ser desenvolvida com base na interação entre indivíduos no mercado. Menger (1985; 2007; 2009), aponta que as primeiras moedas surgiram no decorrer de um longo processo, envolvendo a escolha por uma mercadoria que tivesse uma maior "negociabilidade", e sendo considerada um meio de troca universal. Da mesma forma, Hayek (2017) nota que a moeda é uma das instituições criadas através da ordem ampliada, em que não há um planejamento ou mesmo uma intenção dirigida para a criação dela. Em outras palavras, ela acaba surgindo espontaneamente. Um exemplo desse processo na prática é a criação das moedas virtuais, algo que foi mencionado no início deste artigo.

Com relação ao papel do costume nesse processo, nota-se que a moeda não precisa ser utilizada no mercado tendo por base um decreto governamental ou mesmo uma pressão por um grupo interessado em sua circulação. Mesmo nesses casos, percebe-se que o costume é intrinsecamente necessário para que a moeda seja aceita no mercado, conforme indicado por Menger (1985; 2007), Hayek (2017) e Angeli (2007). Não se utiliza a moeda estatal meramente porque o estado assim o ordenou. Muito pelo contrário, é porque se tem confiança que a moeda pode realizar as suas funções no mercado é que elas são utilizadas. Quando se perde essa confiança, naturalmente as pessoas utilizarão outras formas de comércio como, por exemplo, o escambo, ponto inicial da criação da moeda segundo Menger (2007). Logo, elementos fora do estado acabam por contribuir para a circulação da moeda.

Passando ao papel da moeda no processo de mercado, parte-se da consideração que a economia é, como argumenta Angeli (2007), um ambiente tanto de incerteza fundamental quanto de uma incerteza procedimental. Logo, partindo da incerteza, Hayek (1948a) expõe que o papel da ciência econômica deve ser o de contemplar de que forma o mercado consegue reduzir esta incerteza, e trazer uma maior compatibilidade de planos entre os agentes. Além disso, nesse contexto, a sociedade produz, de forma espontânea e em resposta a esse ambiente de incerteza, instituições que, conforme argumenta Angeli (2007), delimita as respostas dos 
indivíduos a essas incertezas, e permitindo um melhor funcionamento do mercado. Logo, pode-se enxergar a moeda como uma dessas instituições, uma vez que ela facilita a troca entre os indivíduos no mercado, o que aumenta a sua eficiência e permite modificações para retificar falhas nesse sistema.

A quarta discussão, sobre o planejamento central das questões relacionadas ao funcionamento da moeda, parte das possibilidades de sistemas que permitem a compatibilização de planos proposta por Hayek (1948a). De maneira geral, podem-se organizar esses sistemas de uma forma centralizada, em um sistema misto e, finalmente, de forma descentralizada. Podemos transferir esta importante discussão para a questão do funcionamento da moeda no mercado, e a incumbência do estado nesse processo.

Na questão da moeda, o sistema que atualmente prevalece no Brasil e nas grandes economias mundiais é o centralizado ${ }^{16}$. Tal sistema se estrutura em um controle estatal e emissão de moeda através de um banco central. Além disso, por ser uma moeda de curso forçado, podemos utilizar apenas os instrumentos permitidos pela autoridade central para pagamento de contas, contrair e quitar empréstimos e dívidas, entre outros usos da moeda no dia a dia. Esse sistema também possui problemas que são semelhantes aos enfrentados por uma entidade de planejamento central de uma economia, pois enfrenta um problema de descoberta de dados e sinais que surgem continuamente em meio ao mercado, de falências, quedas e aumentos de preços, entre outros, mudanças que são intrínsecas ao uso de moedas em uma economia. Da mesma forma, cabe a essa autoridade central a tarefa de se adaptar a essa constante mudança de sinais em uma economia, se é necessário instituir uma nova possibilidade de pagamento em transações, emitir mais papel moeda ou reduzir essa atividade, entre outras. E a solução desses problemas através de um processo burocrático feita no interior de uma instituição governamental enfrenta obstáculos, pois essas instituições, como diria Hayek (2017), estão tentando agarrar as rédeas de um processo espontâneo que surge em meio ao mercado.

Diante desses problemas enunciados anteriormente, pode-se apontar que talvez seria desejável que esses problemas sejam enfrentados por um processo inteiramente privado e descentralizado. A razão para essa visão encontra-se na observação feita por Hayek (1948b), que o mercado possui em seu funcionamento a possibilidade de uma adaptação e ajustamento a mudanças nas características do funcionamento da economia. Da mesma forma, permite também uma maior disciplina e maior controle na emissão e nas atividades que a moeda exerce no mercado, dispensando o processo burocrático de tomada de decisões em um banco central.

Para discorrer sobre um possível sistema monetário e financeiro privado, utiliza-se a proposta de compreender o processo de mercado a partir de uma epistemologia evolucionária conforme proposta de Barbieri (2001). Desta forma, enxerga-se o mercado como sendo uma instituição de crítica e teste dos planos da situação futura da economia por parte dos indivíduos. Com relação ao funcionamento da moeda e, aproveitando-se da teoria da origem da moeda segundo Menger (2007), percebe-se que a criação de um sistema monetário e financeiro fora

${ }^{16}$ Para descrever este sistema, utilizamos como base a descrição do sistema financeiro conforme proposta por Mankiw (2008). 
do alcance estatal é certamente possível. Diferentes tipos de moeda podem surgir, da mesma forma que surgirão, com elas, novas formas de se efetivar um controle sobre ela, de modo que seu valor e funções sejam mantidas no contexto de mercado. Porém, implica também um processo de tentativa e erro, em que moedas que fracassarem nos dois objetivos serão, aos poucos, depuradas e eliminadas do mercado em nome das moedas que melhor satisfazerem os desejos dos consumidores e produtores. Por ser um sistema centralizado e único, a moeda emitida por decreto governamental carece deste sistema de correção de erros, que surge no contexto de uma economia de mercado desimpedida.

Com relação às possíveis formas de organização inteiramente privada do sistema monetário para o futuro, seria praticamente inútil tentar teorizar sobre qual moeda seria aceita pelo mercado e qual a sua estrutura de funcionamento. Todavia, conforme apontado por Barbieri (2001), essas questões serão resolvidas através de um processo complexo e paulatino de um maior aprendizado por parte dos agentes econômicos, que, através do funcionamento do mercado, acabará por escolher a melhor moeda como também o seu funcionamento, sem, contudo, eliminar qualquer espaço para melhoras no papel do dinheiro na economia.

Por fim, uma última discussão sobre a necessidade de uma chancela da moeda por parte do estado. Segundo Menger (2007), ao Estado caberia este papel, que iria conferir uma dada qualidade, um certo peso, e a garantia de valor ao dinheiro, aperfeiçoando a sua atividade na economia. No entanto, cabe aqui notar que essa discussão feita pelo fundador da Escola Austríaca de Economia foi realizada ao final do século XIX, quando a moeda ainda era em larga escala o ouro, e havia essa necessidade de uma conferência de peso e qualidade da moeda por parte de uma agência. Desta forma, tomando sua discussão sobre o costume, imitação, aprendizado e, especialmente sobre instituições, algo que foi desenvolvido por Barbieri (2001), Angeli (2007) e Hayek (2017), não é impossível que surja, ao longo do tempo, um grupo ou uma autoridade que realize esse importante papel de chancela sobre a moeda. Ao mesmo tempo, é natural que, em um processo de mercado, essa autoridade é constantemente testada e qualquer falha em seu funcionamento pode incorrer na sua substituição por uma outra autoridade que confira valor sobre o dinheiro, ou mesmo que haja competição entre diferentes autoridades. Tal situação é distinta da que existe nos dias de hoje, em que apenas uma instituição detém o monopólio e controle sobre a moeda, na figura do Banco Central.

\section{Considerações Finais}

De modo a cumprir o objetivo deste artigo, foi discutido o papel do Estado na evolução institucional da moeda desde o seu surgimento. Para tanto, foram atingidos os objetivos específicos, visto que foram apresentadas as teorias austríacas acerca da origem da moeda, da ordem ampliada, do processo de mercado e das instituições, apontando seus principais conceitos e ideias. Somadas a essa apresentação, discutiu-se o papel do Estado na origem e evolução institucional do dinheiro, tendo como base as discussões teóricas da Escola Austríaca de Economia. 
Tomando como ponto de partida a discussão acerca da origem da moeda conforme Menger (1985; 2007; 2009), é possível tecer alguns comentários sobre o seu funcionamento em meio à sociedade conforme Hayek (1948a; 1948b; 2017): Por ter uma origem e sistematização descentralizada, ela escapa à capacidade do Estado de exercer um planejamento central de seu funcionamento, visto que ele não possui capacidade de superar a complexidade que é inerente ao desenvolvimento e futura evolução do dinheiro. Dessa forma, ele acaba por prejudicar a moeda como instituição, que, conforme apontado por Angeli (2007), diminui as incertezas do mercado e permite uma correção espontânea das possíveis falhas no desempenho de sua atividade. Além disso, ele impede um contínuo processo de seleção das melhores formas de se empregar a moeda nas interações econômicas entre indivíduos, eliminando planos e ações incompatíveis com a realidade econômica, em concordância com que ensina Barbieri (2001).

O papel do estado na origem e na evolução institucional da moeda, embora pudesse ser justificado em tempos pretéritos através da necessidade de se conferir certeza e confiabilidade à mercadoria que servia como dinheiro, nos tempos atuais, com o rápido avanço da tecnologia, o processo de criação de moedas virtuais e a moeda fiduciária de curso forçado, o Estado acaba travando esse processo, impedindo o mercado de selecionar a moeda que melhor cumpre as suas funções básicas, seja como unidade de conta, como reserva de valor ou como meio de troca, e de corrigir as falhas no funcionamento do sistema financeiro.

É interessante observar que, embora decorrido mais de um século de suas publicações sobre a origem da moeda, permanecem atuais os ensinamentos de Carl Menger sobre esse tema, permitindo um amplo diálogo com outros autores da Escola Austríaca de Economia, sejam eles mais próximos, como no caso de Eduardo Angeli e Fábio Barbieri, ou mais afastados no tempo, a exemplo de Friedrich Hayek. Recomenda-se que, em trabalhos futuros, os pesquisadores possam propor possíveis novas estruturas de funcionamento da moeda no mercado, tomando como ponto de partida os ensinamentos da Escola Austríaca de Economia.

\section{Referências}

ANGELI, Eduardo. Hayek e a teoria das instituições. Dissertação de Mestrado. Campinas: Instituto de Economia/Unicamp, 2007.

BARBIERI, Fábio. O Processo de Mercado na Escola Austríaca Moderna. Dissertação de Mestrado. São Paulo: FEA/USP, 2001.

\section{4.}

História do Debate do Cálculo Econômico Socialista. Tese de Doutoramento. São Paulo: FEA/USP,

. A Economia Falibilista de Hayek. In: XAVIER, Dennys Garcia (org.). F. A. Hayek e a Ingenuidade da Mente Socialista. São Paulo: LVM Editora, 2019.

BARBIERI, Fábio; FEIJÓ, Ricardo Luis Chaves. Metodologia do pensamento econômico: O modo de fazer ciência dos economistas. São Paulo: Atlas, 2013.

BERNARDO, Marcel Pereira; BERNARDELLI, Luan Vinícius; NORI, Rodrigo Braian. A História da Moeda - Uma Proposta de União entre Teoria Econômica e Etnografia. Mises: Revista Interdisciplinar de Filosofia, Direito e Economia. v. 7 n. 2, 2019. Disponível em: https://www.revistamises.org.br/misesjournal/article/view/1113/647. Acesso em: 13 jul 2020. 
CATÃO, Adrualdo de Lima; PINTO, Tamara Luiza Dall Agnol. As Criptomoedas e a Liberdade Contratual no Direito Privado Internacional e no Sistema Jurídico Brasileiro. Mises: Revista Interdisciplinar de Filosofia, Direito e Economia. v. 8, 2020. Disponível em: https://www.revistamises.org.br/misesjournal/article/view/1325/682. Acesso em: 13 jul 2020.

GRAF, Konrad S. Sobre as Origens do Bitcoin: Estágios da Evolução Monetária - Parte I. Mises: Revista Interdisciplinar de Filosofia, Direito e Economia, v. 3. n. 2, 2015. Disponível em: https://www.revistamises.org. br/misesjournal/article/view/779/463. Acesso em: 13 jul 2020.

. Sobre as Origens do Bitcoin: Estágios da Evolução Monetária - Parte II. Mises: Revista Interdisciplinar de Filosofia, Direito e Economia, v. 4. n. 1, 2016. Disponível em: https://www.revistamises.org.br/misesjournal/ article/view/827/511. Acesso em: 13 jul 2020.

HAYEK, Friedrich A. Economics and Knowledge. In: . Individualism and Economic Order. Chicago: The University of Chicago Press, 1948a.

. The Use of Knowledge in Society. In: Individualism and Economic Order. Chicago: The University of Chicago Press, 1948b.

. Denationalisation of Money - The Argument Refined: An Analysis of the Theory and Practice of Concurrent Currencies. London: The Institute of Economic Affairs, 1990.

. Os Erros Fatais do Socialismo: Por que a teoria não funciona na prática?. Barueri: Faro Editorial, 2017.

LORENZON, Geanluca. Ciclos Fatais: Socialismo e Direitos Humanos. São Paulo: Instituto Ludwig von Mises Brasil, 2017.

MANKIW, N. Gregory. Introdução à Economia. São Paulo: Cengage Learning, 2008.

MENGER, Carl. Investigations into the Method of the Social Sciences with Special Reference to Economics. New York: New York University Press, 1985.

. Principles of Economics. Auburn: Ludwig von Mises Institute, 2007.

. The Origins of Money. Auburn: Ludwig von Mises Institute, 2009.

MISES, Ludwig von. The Theory of Money and Credit. New Haven: Yale University Press, 1953.

. Ação Humana: Um Tratado de Economia. São Paulo: Instituto Ludwig von Mises Brasil, 2010.

SENNHOLZ, Hans. The Monetary Writings of Carl Menger. In: ROCKWELL JR.; Llewellyn H. The Gold Standard: Perspectives in the Austrian School. Auburn: Ludwig von Mises Institute, 1992.

ULRICH, Fernando. Bitcoin: A moeda na era digital. São Paulo: Instituto Ludwig von Mises Brasil, 2014.

ZELMANOVITZ, Leonidas. O Padrão-Ouro não é uma alternativa adequada para os problemas monetários atuais. Mises: Revista Interdisciplinar de Filosofia, Direito e Economia. v. 1, n. 1, p. 87-105, 2013. Disponível em: https://www.revistamises.org.br/misesjournal/article/view/195/119. Acesso em: 13 jul 2020.

RECEBIDO: 13 DE FEVEREIRO DE 2021.

APROVADO: 21 DE FEVEREIRO DE 2021. 